\title{
Biofilm Formation and Antibiotic resistance of Enterobacteriaceae isolates from Surgical Site infections in Hôpital de Référence Saint Joseph, Kinshasa, Democratic Republic of Congo
}

Jean-Marie Liesse lyamba ( $\sim$ liesseiyamba@gmail.com )

Universite de Kinshasa https://orcid.org/0000-0002-5942-8365

Rodriguez Musomoni Mabankama

Faculty of Pharmaceutical Sciences, University of Kinshasa

Cyprien Mbundu Lukukula

University of Kinshasa

Joseph Welo Unya

Faculty of Pharmaceutical Sciences, University of Kinshasa

Daniel Tassa Okombe

Faculty of Pharmaceutical Sciences, University of Kinshasa

Benjamin Kodondi Ngbandani

Faculty of Pharmaceutical Sciences, University of Kinshasa

Grégoire Mbusa Vihembo

Faculty of Pharmaceutical Sciences: Siksha O Anusandhan University School of Pharmaceutical

Sciences

Nelson Nsiata Ngoma

Hopital de Référence Saint Joseph

Thierry Mukendi Kajinga

Hôpital Saint Joseph

Odette Mboma Mapipi

Centre National de Pharmacovigilance

Jacques Onokodi Kasongo

Faculty of Pharmaceutical Sciences: Siksha O Anusandhan University School of Pharmaceutical Sciences

NB Takaisi-Kikuni

Faculty of Pharmaceutical Sciences: Siksha O Anusandhan University School of Pharmaceutical Sciences 
Keywords: Antibiotic susceptibility, multidrug resistant bacteria, Surgical site infections, Biofilm formation, OXA-48 producing Enterobacteriaceae, Democratic Republic of Congo.

Posted Date: October 28th, 2020

DOI: https://doi.org/10.21203/rs.3.rs-96885/v1

License: (c) (1) This work is licensed under a Creative Commons Attribution 4.0 International License. Read Full License 


\section{Abstract}

Background: Enterobacteriaceae are one of the most predominant pathogen in surgical site infections. In recent years we oberved increase in resistance among bacteria from surgical site infections. The aim of this study was to evaluate antimicrobial suceptibility pattern of Enterobacteriaceae isolates from surgical site infections, the biofilm formation and the production of OXA-48 carbapenemase.

Methods: A total of 41 Enterobacteriaceae (19 Escherchia coli, 8 Enterobacter sp., 9 Citrobacter sp., and 5 Serratia sp. ) clinical isolates were collected from patients with SSI in Hôpital Saint Joseph (Kinshasa) for diagnostic purposes. The pus samples were cultured and the antibiotic susceptibility profile of the isolates were determined by disk-diffusion method following Clinical and Laboratory Standards Institute 2012 recommendations. OXA-48-producing Enterobacteriaceae were detected using Chromatic ${ }^{\mathrm{TM}}$ OXA-48 chromogenic medium. Crystal Violet Staining Method was used to assess the ability of bacteria strains to form a biofilm.

Results: All Enterobacteriacea isolates studied were biofilm producers and highly resistant to the majority of antibiotics tested. E. coli, Enterobacter sp., Citrobacter sp., and Serratia sp. were $100 \%$ resistant cefotaxime, imipenem, and amoxicillin-clavulanic acid, and ampicillin. Serratia sp. isolates were 100\% and $80 \%$ sensitive to norfloxacine and amikacine respectively. There was relationship between antibiotic resistance and biofilm production. E. coli, Enterobacter sp., and Citrobacter sp. strains were all OXA-48 producers.

Conclusion: The results of the present study demonstrate the emergence of multidrug resistant organisms, the correlation between antibiotic resistance- biofilm formation and OXA-48 production. These results suggest the implementation of antimicrobial resistance survey programm in order to prevent and combat the spread of multidrug resistant organisms in hospital and community in Democratic Republic of Congo.

\section{Introduction}

Surgical site infections (SSIs) are the common postoperative complications and has been estimated to occur in up to $5 \%$ of all procedures [1]. More than $30 \%$ of the Healthcare-associated infections are surgical site infections defined as infections related to operative procedures that occur at or near surgical incisions within 30 days of the procedure or within 90 days if prosthetic materials are implanted at surgery $[2,3]$. SSIs are associated with increased morbidity and mortality. Furthermore, the development of an SSI causes a substantial increase in the clinical and economic burden of surgery. The financial burden of surgery is increased due to the direct costs incurred by prolonged hospitalization of the patient, diagnostic tests, and treatment. Certain patients may also require reoperation after the contraction of an SSI, which is associated with considerable additional costs [4,5]. The outcome of SSIs is partly attributed to increase in antimicrobial resistant bacterial pathogens, which make the choice of empirical therapy more difficult [6]. Studies conducted in many developing countries and in Africa, have indicated high 
antibiotic resistance among Gram-negative bacteria to commonly used antibiotics, leading to a loss of efficacy for treatment of common infections [7-9]. Infections due to antibiotic-resistant gram-negative organisms, including those caused by extended spectrum beta-lactamase (ESBL)-producing Enterobacteriaceae, are increasing worldwide and represent a significant public health threat [10]. The standard treatment of infections caused by ESBL-secreting Enterobacteriaceae is based on the use of carbapenems [11]. However, their usefulness is threatened by the emergence and spread of bacteria that produce carbapenemase enzymes hospital and community $[12,13]$. Carbapenemases come from ambler class $A$ or $D$ serine $\beta$-lactamases and ambler class B metallo- $\beta$-lactamases (MBLs). $K$. pneumoniae carbapenemase (KPC-Class A), New Delhi metallo- $\beta$-lactamase (NDM-Class B), Verona integron-encoded metallo- $\beta$-lactamase (VIM-Class B), Imipenemase metallo- $\beta$-lactamase (IMP-Class B), and Oxacillinase-48 (OXA-48-Class $D$ ) variants are the most common carbapenemases in carbapenemase producing Enterobacteriaceae (CPE) [12,13]. OXA-48 carbapenemase is one of the several carbapenemases that have been described so far; the high prevalence of infections caused by OXA-48 producers is well established in Africa, Europ and elsewhere [14].

Pathogenesis of Enterobacteriaceae is attributable not only to antibiotic resistance, which complicates the treatment of SSIs, but also to other factors. One of these factors is the ability of bacteria to adhere to a biotic or an abiotic surface and to form a biofilm [15]. There is a high probability that microorganisms will contaminate the site of incision or excision in a surgical

wound. If a bacterium is able to attach onto a biological surface it rapidly changes the proteins it expresses and as such becomes sessile and significantly different phenotypically, when compared with its planktonic counterpart [16].

A biofilm can be defined as a community of microorganisms that are attached to each other, and/or a surface, encased within a matrix of extracellular polymeric substance, appearing as microcolonies or aggregates of cells [17]. The presence of biofilms as a potential cause of SSIs may explain the sometimes-disappointing response obtained from traditional approaches such as promoting drainage, systemic antibiotics or delayed closure [18].

The goal of the present study was to analyze the capacity to form biofilm of 41 Enterobacteriaceae strains isolated from SSIs and to evaluate the production of OXA-48 carbapenemase. We investigated also the correlation between biofilm formation, antimicrobial resistance and OXA-48 production in Enterobacteriaceae isolated from patients with SSIs.

\section{Material And Methods}

A total of 41 Enterobacteriaceae strains from patients with SSI (19 E. coli, 8 Enterobacter sp., 9 Citrobacter sp., and 5 Serratia sp.) were studied. Isolates were received from Hôpital de Référence Saint Joseph (Kinshasa). The clinical samples were collected for diagnostic purposes by the bacteriology laboratories of this hospital, and were from hospitalized patients. 
Isolated strains were identified using microbiological conventional methods including Gram staining, oxidase tests, indole and urease production, citrate utilization, hydrogen sulphide, gas production and fermentation of sugars, phenylalanine deaminase, lysine decarboxylase (L.D.C.), ornithine decarboxylase (O.D.C.), arginine dihydrolase (A.D.H.) tests, and methyl red reaction. In our laboratory, strains were picked on MacConkey agar (Liofilchen, Roseto degli Abruzzi, Italy), and were confirmed as Enterobacteriaceae species using the same tests. All cultures were maintained on trypticase soy agar (Liofilchen, Roseto degli Abruzzi, Italy).

\section{Antibiotic susceptibility tests}

Antibiograms of each isolated Enterobacteriaceae strains using the diffusion method on Mueller Hinton Agar were realized with the following antibiotic disks (Liofilchen, Roseto degli Abruzzi, Italy): ampicillin $(30 \mu \mathrm{g})$, amoxicillin-clavulanic acid $(30 \mu \mathrm{g})$, amikacin $(30 \mu \mathrm{g})$, cefotaxime $(30 \mu \mathrm{g})$, imipenem $(10 \mu \mathrm{g})$, norfloxacin $(5 \mu \mathrm{g})$, ciprofloxacin $(5 \mu \mathrm{g})$, kanamycin $(30 \mu \mathrm{g})$. After incubation of plates at $37^{\circ} \mathrm{C}$ for 24 hours, diameters of zone of inhibition were measured. Evaluation of the results was done according to the criteria of Clinical Laboratory Standards Institute (CLSI) [19]. E. coli ATCC 25922 were used for quality control. The results of antibiotic susceptibility tests from hospital were confirmed in our laboratory using the same antibiotic disks.

\section{Biofilm formation assay}

In present study, we screened all isolates for their ability to form biofilm by Crystal Violet Staining Method (CVSM) as previously described [20], with modifications. A suspension equivalent to the McFarland 0.5 turbidity standard was prepared in trypticase soya broth (Liofilchen, Roseto degli Abruzzi, Italy) for each strain. Accuracy of bacterial counts in the suspension was confirmed by serial dilution in log steps. Polystyrene sterile strips were inoculated with $200 \mu \mathrm{L}$ of each calibrated bacterial suspension and incubated for 24 hours at $35^{\circ} \mathrm{C}$ in a humid atmosphere. A control well was inoculated with sterile medium. Each strain was evaluated in triplicate. Medium was removed from the wells which were washed 3 times with $200 \mu \mathrm{L}$ sterile distilled water. The strips were air- dried for 45 min and the adherent cells were stained with $200 \mu \mathrm{L}$ of $0.1 \%$ Crystal violet solution. After $45 \mathrm{~min}$, the dye was eliminated and the wells were washed 5 times with $300 \mu \mathrm{L}$ of sterile distilled water to remove excess stain. The dye incorporated by the cells forming a biofilm was dissolved with $200 \mu \mathrm{L}$ of $33 \%(\mathrm{v} / \mathrm{v}$ ) glacial acetic acid and the absorbance of the well was obtained by means of enzyme-linked immunosorbent assay (ELISA) reader, at the wavelength of $540 \mathrm{~nm}$. The results were expressed as variation of Optical Density (OD)540 $\mathrm{nm}$ (OD540 nm sample - OD540 nm control). These OD values were considered as an index of bacteria adhering to surface and forming biofilms. For interpretation of biofilm production, the average of the three wells was calculated, and the criterion proposed by Ramos-Vivas et al. [21] was adopted: OD $\leq$ 0.05 , non-biofilm producer; OD > 0.05-0.1 weak biofilm producer; OD > 0.1-0.3 moderate biofilm producer; and OD $>0.3$ strong biofilm producer.

\section{Detection of OXA-48 producers}


OXA-48-producing Enterobacteriaceae were detected on Chromatic ${ }^{\mathrm{TM}}$ OXA-48 chromogenic medium (Liofilchem, Roseto degli Abbruzzi, Italy). After incubation at $37^{\circ} \mathrm{C} / 24$ - 48 hours, the color and the morphology of the colonies were observed and the results interpreted according to the supplier's instructions as follow: red colony (E. coli-producing OXA-48), blue-violet colony (Klebsiella sp. producing OXA-48), blue-green (Enterobacter sp. producing OXA-48), blue colony with red halo (Citrobacter sp. producing OXA-48). E. coli ATCC 25922 was used for quality control.

\section{Statistical analysis}

GraphPad software package was used for statistical analysis. Chi-square test was applied. $P$-value $<0.05$ was considered statistically significant.

\section{Results}

\section{Antibiotic susceptibility}

The E. coli, Citrobacter sp., Enterobacter sp., Serratia sp. strains from SSIs were highly resistant to the majority of antibiotics tested. E. coli isolates were particularly $100 \%$ resistant to ampicillin, kanamycin, amoxicillin - clavulanic acid, cefotaxime, and imipenem. Serratia sp. isolates were fully sensitive to norfloxacin and $80 \%$ sensitive to amikacin. Multidrug resistance (MDR) was observed in Enterobacteriaceae isolated from SSIs (Table 1).

Table1 Antibiotic susceptibility pattern of Enterobacteriaceae isolated from SSIs

\begin{tabular}{|l|c|c|c|c|c|c|c|c|}
\hline Antibiotics & \multicolumn{2}{|c|}{ E. coli } & \multicolumn{2}{c|}{ Enterobacter sp. } & \multicolumn{2}{c|}{ Citrobacter sp. } & \multicolumn{2}{c|}{ Serratia sp. } \\
\hline & Resistant & Sensitive & Resistant & Sensitive & Resistant & Sensitive & Resistant & \multicolumn{2}{c|}{ Sensitive } \\
\hline & $\mathrm{N}^{\circ}(\%)$ & $\mathrm{N}^{\circ}(\%)$ & $\mathrm{N}^{\circ}(\%)$ & $\mathrm{N}^{\circ}(\%)$ & $\mathrm{N}^{\circ}(\%)$ & $\mathrm{N}^{\circ}(\%)$ & $\mathrm{N}^{\circ}(\%)$ & $\mathrm{N}^{\circ}(\%)$ \\
\hline Ampicillin & $19(100.0)$ & $0(0.0)$ & $8(100.0)$ & $0(0.0)$ & $9(100.0)$ & $0(0.0)$ & $5(100.0)$ & $0(0.0)$ \\
\hline $\begin{array}{l}\text { Amoxicillin - } \\
\text { clavulanic acid }\end{array}$ & $19(100.0)$ & $0(0.0)$ & $8(100.0)$ & $0(0.0)$ & $9(100.0)$ & $0(0.0)$ & $5(100.0)$ & $0(0.0)$ \\
\hline Cefotaxime & $19(100.0)$ & $0(0.0)$ & $8(100.0)$ & $0(0.0)$ & $8(88,9)$ & $1(11.1)$ & $5(100.0)$ & $0(0.0)$ \\
\hline Norfloxacin & $16(84.2)$ & $3(15.8)$ & $4(50.0)$ & $4(50.0)$ & $5(55.6)$ & $4(44.4)$ & $0(0.0)$ & $5(100.0)$ \\
\hline Ciprofloxacin & $16(84.2)$ & $3(15.8)$ & $5(62.5)$ & $3(37.5)$ & $6(66.7)$ & $3(33.3)$ & $2(40.0)$ & $3(60.0)$ \\
\hline Imipenem & $19(100.0)$ & $0(0.0)$ & $8(100.0)$ & $0(0.0)$ & $9(100.0)$ & $0(0.0)$ & $5(100.0)$ & $0(0.0)$ \\
\hline Amikacin & $12(63.3)$ & $7(36.8)$ & $2(22.2)$ & $6(77.8)$ & $2(22.2)$ & $7(77.8)$ & $1(20.0)$ & $4(80.0)$ \\
\hline Kanamycin & $19(100.0)$ & $0(0.0)$ & $8(100.0)$ & $0(0.0)$ & $6(66.7)$ & $3(33.3)$ & $5(100.0)$ & $0(0.0)$ \\
\hline
\end{tabular}

\section{Biofilm formation}

The results of biofilm formation of different clinical isolates studied are presented in Table 2 and Figure 1. Ten (52.6\%), 9 (47.4\%) of E. coli strains were strong biofilm producers (SBP) and moderate biofilm producers (MBP) respectively. For a total of 9 Enterobacter sp. studied for biofilm formation, 6 (62.5\%) 
were SBP and 3 (33.5\%) were MBP. Five (66.7\%) Citrobacter strains have formed a strong biofilm and 3 $(33.3 \%)$ have produced moderate biofilm. Out of 5 Serratia sp. strains, $3(60.0 \%)$ were SBP and $2(40.0 \%)$ were MBP.

Table 2 Summary of biofilm producers isolates

\begin{tabular}{|c|c|c|c|c|}
\hline \multirow{3}{*}{$\begin{array}{l}\text { Classification } \\
\text { according to bacterial } \\
\text { biofilm production }\end{array}$} & \multicolumn{4}{|c|}{ Enterobacteriaceae strains isolated from SSIs } \\
\hline & $\mathrm{N}(\%)$ & $\mathrm{N}(\%)$ & $\mathrm{N}(\%)$ & $\mathrm{N}(\%)$ \\
\hline & E. coli & $\begin{array}{c}\text { Enterobacter } \\
\text { sp. }\end{array}$ & $\begin{array}{l}\text { Citrobacter } \\
\text { sp. }\end{array}$ & Serratia sp. \\
\hline $\begin{array}{l}\text { Strong biofilm } \\
\text { producer } \\
(O D>0.3)\end{array}$ & $10(52.6)$ & $5(62.5)$ & $6(66.7)$ & $3(60.0)$ \\
\hline $\begin{array}{l}\text { Moderate biofilm } \\
\text { producer }(O D>0.1- \\
0.3\end{array}$ & $9(47.4)$ & $3(37.5)$ & $3(33.3$ & $2(40.0)$ \\
\hline $\begin{array}{l}\text { Weak biofilm } \\
\text { producer }(O D>0.05- \\
0.1)\end{array}$ & $0(0.0)$ & $0(0.0)$ & $0(0.0)$ & $0(0.0)$ \\
\hline $\begin{array}{l}\text { Non-biofilm producer } \\
(O D \leq 0.05)\end{array}$ & $0(0.0)$ & $0(0.0)$ & $0(0.0)$ & $0(0.0)$ \\
\hline TOTAL & $19(100.0)$ & $8(100.0)$ & $9(100.0)$ & $5(100.0)$ \\
\hline
\end{tabular}

\section{Resistance pattern of Enterobacteriaceae strains among biofilm producers}

Resistance to ampicillin, amoxicillin-clavulanic acid, cefotaxime, amikacin, kanamycin, norfloxacin, and imipenem were higher in SBP than in MBP in E. coli isolates. Similar results were obtained for Enterobactersp., Citrobacter sp., and Serratia sp. isolates (Table 3). Regarding MDR, relationship was found between multidrug resistance and biofilm formation (Table 4). 


\begin{tabular}{|c|c|c|c|c|c|c|c|c|c|c|c|c|}
\hline \multirow[t]{2}{*}{ Antibiotics } & \multicolumn{3}{|c|}{ E. coli } & \multicolumn{3}{|c|}{ Enterobacter sp. } & \multicolumn{3}{|c|}{ Citrobacter sp. } & \multicolumn{3}{|c|}{ Serratia sp. } \\
\hline & $\begin{array}{l}\mathrm{SBP}, \\
\mathrm{N}=10\end{array}$ & $\begin{array}{l}\text { MPB, } \\
N=9\end{array}$ & $\begin{array}{l}\text { Total } \\
\text { resistant }\end{array}$ & $\begin{array}{l}\mathrm{SBP}, \\
\mathrm{N}=5\end{array}$ & $\mathrm{MBP}, \mathrm{N}=3$ & $\begin{array}{c}\text { Total } \\
\text { resistant }\end{array}$ & $\mathrm{SBP}, \mathrm{N}=6$ & $\begin{array}{l}\text { MBP, } \\
N=3\end{array}$ & $\begin{array}{c}\text { Total } \\
\text { resistant }\end{array}$ & $\mathrm{SBP}, \mathrm{N}=3$ & $\begin{array}{l}\mathrm{MBP}, \\
\mathrm{N}=2\end{array}$ & $\begin{array}{c}\text { Total } \\
\text { resistant }\end{array}$ \\
\hline & $\mathrm{N}^{\circ}(\%)$ & $\mathrm{N}^{\circ}(\%)$ & $\mathrm{N}^{\circ}(\%)$ & $\mathrm{N}^{\circ}(\%)$ & $\mathrm{N}^{\circ}(\%)$ & $\mathrm{N}^{\circ}(\%)$ & $\mathrm{N}^{\circ}(\%)$ & $\mathrm{N}^{\circ}(\%)$ & $\mathrm{N}^{\circ}(\%)$ & $\mathrm{N}^{\circ}(\%)$ & $\mathrm{N}^{\circ}(\%)$ & $\mathrm{N}^{\circ}(\%)$ \\
\hline Ampicillin & $10(100)$ & $9(100)$ & $19(100)$ & $5(100)$ & $3(100)$ & $8(100)$ & $6(100)$ & $3(100)$ & $9(100)$ & $3(100)$ & $2(100)$ & $5(100)$ \\
\hline $\begin{array}{l}\text { Amoxicillin - } \\
\text { clavulanic } \\
\text { acid }\end{array}$ & $10(100)$ & $9(100)$ & $19(100)$ & $5(100)$ & $3(100)$ & $8(100)$ & $6(100)$ & $3(100)$ & $9(100)$ & $3(100)$ & $2(100)$ & $5(100)$ \\
\hline Cefotaxime & $10(100)$ & $9(100)$ & $19(100)$ & $5(100)$ & $3(100)$ & $8(100)$ & $5(83.3)$ & $3(100)$ & $8(88.8)$ & $3(100)$ & $2(100)$ & $5(100)$ \\
\hline Norfloxacin & $10(100)$ & $6(66.6)$ & $16(84.2)$ & $3(60)$ & $1(33.3)$ & $4(50)$ & $3(50)$ & $1(33.3)$ & $4(44.4)$ & $0(0)$ & $\mathrm{O}(0)$ & $0(0)$ \\
\hline Ciprofloxacin & $10(100)$ & $6(66.6)$ & $16(84.2)$ & $4(80)$ & $1(33.3)$ & $5(62.5)$ & $4(66.6)$ & $1(33.3)$ & $5(55.5)$ & $3(100)$ & $0(0)$ & $3(60)$ \\
\hline Imipenem & $10(100)$ & $9(100)$ & $19(100)$ & $5(100)$ & $3(100)$ & $8(100)$ & $6(100)$ & $3(100)$ & $9(100)$ & $3(100)$ & $2(100)$ & $5(100)$ \\
\hline Amikacin & $9(90)$ & $3(33.3)$ & $12(63.1)$ & $2(40)$ & $0(0)$ & $2(25)$ & $2(33.3)$ & $0(0)$ & $2(22.2)$ & $1(33.3)$ & $0(0)$ & $1(20)$ \\
\hline Kanamycin & $10(100)$ & $9(100)$ & $19(100)$ & $5(100)$ & $3(100)$ & $8(100)$ & $6(100)$ & $2(66.6)$ & $8(88.8)$ & $3(100)$ & $2(100)$ & $5(100)$ \\
\hline
\end{tabular}

SBP: strong biofilm producers; MBP: moderate producers; ND: not determine 


\begin{tabular}{|c|c|c|c|c|}
\hline \multirow{2}{*}{$\begin{array}{l}\text { Number of antibiotic } \\
\text { category }\end{array}$} & \multicolumn{3}{|c|}{ Number of $E$. coli biofilm phenotype } & \multirow{2}{*}{\begin{tabular}{|l}
$\begin{array}{l}\text { Total number of } \\
\text { isolates }\end{array}$ \\
\end{tabular}} \\
\hline & SBP & MBP & NBP & \\
\hline & $\mathbf{N}^{\circ}(\%)$ & $\mathbf{N}^{\circ}(\%)$ & $\mathbf{N}^{\circ}(\%)$ & $\mathbf{N}^{\circ}(\%)$ \\
\hline 8 & $9(90.0)$ & $1(11.1)$ & $0(0.0)$ & $10(52.6)$ \\
\hline 7 & $1(10.0)$ & $6(66.7)$ & $0(0.0)$ & $7(36.9)$ \\
\hline 6 & $0(0.0)$ & $2(22.2)$ & $0(0.0)$ & $2(10.5)$ \\
\hline \multirow[t]{2}{*}{ TOTAL } & $10(52.6)$ & 9(47.4) & $0(0.0)$ & $19(100.0 \%)$ \\
\hline & \multicolumn{3}{|c|}{ Number of Enterobacter sp. biofilm phenotype } & \\
\hline 8 & $2(40.0)$ & $0(0.0)$ & $0(0.0)$ & $2(25.0)$ \\
\hline 7 & $1(20.0)$ & $1(33.3)$ & $0(0.0)$ & $2(25.0)$ \\
\hline 6 & $1(20.0)$ & $0(0.0)$ & $0(0.0)$ & $1(12.5)$ \\
\hline 5 & $1(20.0)$ & $2(66.7)$ & $0(0.0)$ & $3(37.5)$ \\
\hline \multirow[t]{2}{*}{ TOTAL } & $5(62.5)$ & $3(37.5)$ & $0(0.0)$ & $8(100.0)$ \\
\hline & \multicolumn{3}{|c|}{ Number of Citrobacter sp. biofilm phenotype } & \\
\hline 8 & $2(33.2)$ & $0(0.0)$ & $0(0.0)$ & $2(22.2)$ \\
\hline 7 & $1(16.7)$ & $1(33.3)$ & $0(0.0)$ & $2(22.2)$ \\
\hline 6 & $1(16.7)$ & $0(0.0)$ & $0(0.0)$ & $1(11.1)$ \\
\hline 5 & $1(16.7)$ & $2(66.7)$ & $0(0.0)$ & $3(33.4)$ \\
\hline 4 & $1(16.7)$ & $0(0.0)$ & $0(0.0)$ & $1(11.1)$ \\
\hline \multirow[t]{2}{*}{ TOTAL } & $6(66.7)$ & $3(33.3)$ & $0(0.0)$ & $9(100.0)$ \\
\hline & \multicolumn{3}{|c|}{ Number of Serratia sp. biofilm phenotype } & \\
\hline 7 & $1(33.3)$ & $0(0.0)$ & $0(0.0)$ & $1(20.0)$ \\
\hline 6 & $2(66.7)$ & $0(0.0)$ & $0(0.0)$ & $2(40.0)$ \\
\hline 5 & $0(0.0)$ & $2(100)$ & $0(0.0)$ & $2(40.0)$ \\
\hline TOTAL & $3(60.0)$ & $2(40.0)$ & $0(0.0)$ & $5(100.0)$ \\
\hline
\end{tabular}

SBP: strong biofilm producer; MBP: moderate biofilm producer; NBP: non-biofilm producer.

\section{OXA- 48 Producers}

All E. coli, Enterobactersp., and Citrobacter sp. strains isolated from SSI were found to be OXA-48 producers. 
Out of 19 OXA-48 producing E. coli strains isolated from SSI, 10 were SBP and 9 were MBP. Five OXA-48 producing Enterobacter sp. isolates from SSI were SBP and 3 were MBP. Out of 9 OXA-48 producing Citrobacter sp. strains isolated from SSI, 6 were SBP and 3 were MBP.

Table 5 OXA-48-producing Enterobacteriaceae strains and biofilm phenotype

\begin{tabular}{|l|l|l|l|l|l|}
\hline & \multicolumn{3}{|l|}{ OXA-48 producers according to biofilm phenotype } & Typical color colony \\
\hline & SBP, $\mathbf{n}(\%)$ & MBP, $\mathbf{n}(\%)$ & NBP, $\mathbf{n}(\%)$ & $\begin{array}{l}\text { Total OXA-48 } \\
\text { producers, } \mathbf{n}(\%)\end{array}$ & \\
\hline $\begin{array}{l}\text { Escherichia } \\
\text { coli }\end{array}$ & $10(52.6)$ & $9(47.4)$ & $0(0.0)$ & $19(100.0)$ & Red \\
\hline $\begin{array}{l}\text { Enterobacter } \\
\text { sp. }\end{array}$ & $5(62.5)$ & $3(37.5)$ & $0(0.0)$ & $8(100.0)$ & Blue-green \\
\hline \begin{tabular}{l} 
Citrobacter sp. \\
\hline Serratia sp.
\end{tabular} & $6(66.7)$ & $3(33.3)$ & $0(0.0)$ & $9(100.0)$ & Blue with red halo \\
\hline
\end{tabular}

SBP: strong biofilm producer; MBP: moderate biofilm producer; NBP: non-biofilm producer

\section{Discussion}

Enterobacteriaceae are known as a significant cause of SSIs [22, 23]. The emergence of microorganisms resistant to multiple antibiotics used in the treatment of infections has become an important health problem worldwide, particularly in African countries [24]. Antibiotic sensitivity testing of the isolates showed higher rates of multidrug resistant (MDR) strains of these organisms in SSIs. E. coli, Enterobacter sp., Citrobacter sp., and Serratia showed higher resistance to $\beta$-lactam antibiotics (ampicillin, amoxicillinclavulanic acid, cefotaxime), quinolones (ciprofloxacin, norfloxacin), aminoglycosides (amikacin and kanamycin), carbapenem (imipenem). This high resistance of organisms to the most commonly used antibiotics was reported from many studies [25-29]. 100\% of Enterobacteriaceae strains were resistant to imipenem. Our results are not consistence with a report from Iran in which $100 \%$ of Enterobacteriaceae isolated from SSIs sensitives to this antibiotic [30]. In this study, we detected OXA-48-producing strains among different enterobacterial species isolated in samples from patients with SSIs. E. coli, Citrobacter sp., and Enterobacter sp. strains were 100\% OXA-48-producers. Reports from many African studies showed the spread of carbapenemase-producing bacteria [31]. Investigations done in many African countries such as Tunisia, Libya, Tanzania, Senegal, and Morocco, have shown that K. pneumoniae was the most frequently OXA-48 producer [32]. But in this study, we observed a high rate of OXA-48 producers among E. coli, Enterobacter sp and Citrobactersp strains (100\%). Due to limited laboratory facilities (molecular tools), we were unable to investigate the production of OXA-48 by Serratia sp. strains. This organism is inhibited in Chromatic ${ }^{\mathrm{TM}} \mathrm{OXA}-48$ medium. Only Klebsiella sp, E. coli, Citrobacter and 
Enterobacter sp. produce colonies on this medium. Using Polymerase Chain Reaction, other reports have demonstrated that K. pneumoniae, E. coli, C. freundii, P. mirabilis, Enterobacter sp. and Serratia marcescens are OXA-48 producers [33,34]. The results of the current study demonstrated that SSIs due OXA-48-carbapenemase-producing Enterobacteriaceae is a major clinical challenge.

In this study the detection of biofilm formation was performed using CVSM. All Enterobacteriaceae (100\%) isolates from SSIs were biofilm producers. Microbial cell adherence to surfaces and the development of multi-cellular communities is a key step in infection. Furthermore, bacteria biofilms can play a critical role in SSIs [35] and can delay wound healing $(18,36)$. We demonstrated also a high variability in biofilm biomass production among isolates from SSIs (Figure 1). Biofilm formation depends on many factors such as environment, sugar content and concentration (glucose versus lactose), geographical origin, types of specimen, surface adhesion characteristics, proteolytic enzymes, and biofilm associated genes [37-39]. These factors could be involved in the high number of biofilm positive strains as observed in the present study. The biofilm producing-Enterobacteriaceae from SSIs were very resistant to antibiotics. A biofilm creates a protected mode of growth that allows bacteria to survive in hostile environments protected from host defenses and the action of antibiotics. Bacteria in biofilms show high antibiotic resistance because of the difficulty the drugs have in penetrating the biofilm (antibiotics do not reach sufficient concentrations in any part of the biofilm) and the metabolism of bacteria at the base of the biofilm (they are metabolically inactive and therefore resistant to some antibiotics [16]. The association between biofilm and antibiotic resistance was noted to be statistically significant $(P<0.05)$ in most of the antibiotics (ampicillin, amoxicillin-clavulanic acid, cefotaxime, imipenem, and kanamycin). The correlation between antibiotic resistance and biofilm production has been documented in other studies [40-42].

The association between OXA-48 production and biofilm formation was observed for E. coli, Citrobacter sp., and Enterobactersp. ( $P$ < 0.05). Imipenem, ampicillin, amoxicillin-clavulanic acid, and cefotaxime was $100 \%$ ineffective against OXA-48 positive strains. OXA-48 are enzymes that are responsible for resistance of bacteria toward carbapenems. It is well known that carbapenems are the most effective antibiotics for the treatment of infections resulted from MDR strains; recently, the increasing occurrence of carbapenem-resistant isolates of Enterobacteriaceae has become a global concern (12-14). Many factors could be responsible for the increasing of resistance in DRC as demonstrated in the present study. Among them are some frequent societal behaviors (such as self-medication), inadequate healthcare infrastructure (insufficiently trained prescribers and inadequate diagnostic tools), and an uncontrolled drug sector (antibiotics sold over-the-counter, improperly stored, counterfeit, and/or expired [43], as well as biofilm ability of strains and the acquisition of resistance genes [40-42].

\section{Conclusion}

There was higher resistance rate among biofilm producing E. coli, Citrobacter sp, Enterobacter sp , and Serratia sp. isolates to the majority of antibiotic tested except norfloxacin and amikacin for Serratia sp. The higher resistance rate of strains to imipenem and to other antibiotics suggests the implementation 
and development of national policies and plans to prevent and combat the spread of resistant bacteria in community and hospital setting.

\section{Abbreviations}

ADH: Arginine dihydrolase; ATCC: American type culture collection; CLSI: Clinical and laboratory standards institute; CVSM: Crystal Violet Staining Method; DRC: Democratic Republic of Congo; ELISA: Enzyme-linked immunosorbent assay; L.D.C: Lysine decarboxylase; MBP: Moderate biofilm producer; MDR: Multidrug resistance; NBP: Non-biofilm producer; OD: Optical density; ODC: Ornithine decarboxylase; OXA-48: Oxacillinase-48; SSIs: Surgical site infections; SBP: Strong biofilm producer.

\section{Declarations}

\section{Consent for publication}

Not applicable.

\section{Availability of data and materials}

The datasets analyzed during the current study are not publicly available. Laboratory has not provided us information on patients. Results of antibiograms and biofilm tests can be provided by the corresponding author on reasonable request.

\section{Funding}

Not applicable

\section{Acknowledgements}

Not applicable

\section{Authors' contributions}

Jean-Marie LIESSE IYAMBA contributed to the conception of the study, the preparation of the manuscript and the statistical analyses. Ntondo za Balega Takaisi-Kikuni and Jacques Onokodi Kasongo contributed to analysis and the preparation of manuscript. Thierry Mukendi Kajinga and Nelson Nsiata contributed to the collection of samples and to antimicrobial susceptibility tests at Hôpital Saint Joseph. Cyprien Mbundu Lukukula and Joseph Welo Unya contributed to the processing of samples and to antibiotic susceptibility tests in our laboratory. Daniel Tassa Okombe, Benjamin Kodondi Ngbandani, and Grégoire Mbusa Vihembo contributed to OXA-48 carbapenemase screening and biofilm formation tests. Odette Mboma Mapipi analysed litterature data. All the authors have read and approved the final version of the manuscript.

\section{Competing interests}


The authors declare that they have no competing interests.

\section{Ethical approval}

Not required.

\section{Author details}

${ }^{1}$ Laboratory of Experimental and Pharmaceutical Microbiology, Faculty of Pharmaceutical Sciences, University of Kinshasa, Kinshasa, Democratic Republic of Congo.

${ }^{2}$ Service de Microbiologie, Hôpital de Référence Saint Joseph, Limete-Kinshasa, Democratic Republic of Congo

${ }^{3}$ Service de Médecine Interne, Hôpital de Référence Saint Joseph, Limete-Kinshasa, Democratic Republic of Congo

${ }^{4}$ Centre National de Pharmacovigilence, University of Kinshasa, Kinshasa, Democratic Republic of Congo.

\section{References}

1. Cheadle WG. Risk factors for surgical site infection. Surg Infect (Larchmt). 2006;7 Suppl 1:S7-11. https://doi.org/10.1089/sur.2006.7.s1-7.

2. Horan TC, Gaynes RP, Martone WJ, Jarvis WR, Emori TG. CDC definitions of nosocomial surgical site infections, 1992: a modification of CDC definitions of surgical wound infections. Infect Control Hosp Epidemiol.1992;13(10):606-8.

3. Allegranzi B, Bischoff $\mathrm{P}$, de Jonge $\mathrm{S}$, et al. New WHO recommendations on preoperative measures for surgical site infection prevention: an evidence-based global perspective. Lancet Infect Dis. 2016;16(12):e276-e87. https://doi.org/10.1016/s1473-3099(16)30398-x.

4. Badia JM, Casey AL, Petrosillo N, Hudson PM, Mitchell SA, Crosby C. Impact of surgical site infection on healthcare costs and patient outcomes: a systematic review in six European countries. J Hosp Infect. 2017;96(1):1-15.https://doi.org/10.1016/j.jhin.2017.03.004.

5. O'Keeffe AB, Lawrence T, Bojanic S. Oxford craniotomy infections database: a cost analysis of craniotomy infection. Br J Neurosurg. 2012;26:265-

9.https://doi.org/10.3109/02688697.2011.626878.

6. Weigelt JA, Lipsky BA, Tabak YP, Derby KG, Kim M, Gupta V: Surgical site infections: causative pathogens and associated outcomes. Am J Infect Control. 2010; 38:112-120. https://doi.org/10.1016/j.ajic.2009.06.010.

7. Le Doare K, Bielicki J, Heath PT, Sharland M. Systematic review of antibiotic resistance rates among gram-negative bacteria in children with sepsis in resource-limited countries. J Pediatric Infect Dis Soc. 2015;4:11-20.https://doi.org/10.1093/jpids/piu014. 
8. Carroll M, Rangaiahagari A, Musabeyezu E, Singer D, Ogbuagu O. Five-year antimicrobial susceptibility trends among bacterial isolates from a tertiary health-care facility in Kigali, Rwanda. Am J Trop Med Hyg. 2016;95:1277-83.https://doi.org/10.4269/ajtmh.16-0392.

9. Kumburu HH, Sonda T, Mmbaga BT, Alifrangis M, Lund O, Kibiki G, Aarestrup FM. Patterns of infections, aetiological agents, and antimicrobial resistance at a tertiary care hospital in northern Tanzania. Tropical Med Int Health. 2017; 22:454-64.https://doi.org/10.1111/tmi.12836.

10. Cosgrove SE. The relationship between antimicrobial resistance and patient outcomes: mortality, length of hospital stay, and health care costs. Clin Infect Dis. 2006 Jan 15;42 Suppl 2:S82-9. https://doi.org/10.1086/499406.

11. Pana ZD and Zaoutis T. Treatment of extended-spectrum $\beta$-lactamase-producing Enterobacteriaceae (ESBLs) infections: what have we learned until now? F1000Res. 2018;7:F1000 Faculty Rev-1347. https://doi.org/10.12688/f1000research.14822.1.

12. Potter RF, D'Souza AW, Dantas G. The rapid spread of carbapenem-resistant Enterobacteriaceae. https://doi.org/10.1016/j.drup.2016.09.002.

13. van Duin D and Doi. The global epidemiology of carbapenemase-producing Enterobacteriaceae. Virulence. 2017; 8(4): 460-69. https://doi.org/10.1080/21505594.2016.1222343.

14. Poirel L, Potron A, Nordmann P. OXA-48-like carbapenemases: the phantom menace. J Antimicrob Chemother. 2012; 67 (7): 1597-606. https://doi.org/10.1093/jac/dks121.

15. Donlan RM. Biofilms: microbial life on surfaces. Emerg Infect Dis. 2002; 8 (9): 881-90. https://doi.org/10.3201/eid0809.020063.

16. Costerton JW, Stewart PS, Greenberg EP. Bacterial biofilms: a common cause of persistent infections. Science. 1999; 284(5418): 1318-22.https://doi.org/10.1126/science.284.5418.1318.

17. Percival et al. Biofilms and Wounds: An Identification algorithm and potential treatment options. Adv Wound Care (New Rochelle). 2015;4(7):389-397. https://doi.org/10.1089/wound.2014.0574.

18. Wolcott R, Cutting KF, Dowd SE. Surgical site infections: biofilms, dehiscence and delayed healing. Wounds UK. 2008; 4 (4):108-13.

19. Clinical Laboratory Standards Institute (CLSI). CLSI document M100S-S22. Performance standards for antimicrobial susceptibility testing: Twenty second informational supplement ed. Wayne: CLSI; 2012.

20. Chavant P, Gaillard-Martinie B, Talon R, Hébraud M, Bernardi T. A new device for rapid evaluation of biofilm formation potential by bacteria. J Microbiol Methods. 2007;68(3):605-612. https://doi.org/10.1016/j.mimet.2006.11.010.

21. Ramos-Vivas J, Chapartegui-González I, Fernández-Martínez M, et al. Biofilm formation by multidrug resistant Enterobacteriaceae strains isolated from solid organ transplant recipients. Sci Rep.2019;9(1):8928. https://doi.org/10.1038/s41598-019-45060-y.

22. Lehner S, Grabein B, Pfaller P, Kopp R. Relevance of ESBL-producing pathogens for clinical surgery: diagnostics, therapy, and prevention. Chirurg. 2009;80(6):527-36. https://doi.org/10.1007/s00104008-1664-x. 
23. Jolivet S, Lescure FX, Armand-Lefevre L, Raffoul R, Dilly MP, Ghodbane W, Nataf P, Lucet JC. Surgical site infection with extended-spectrum $\beta$-lactamase-producing Enterobacteriaceae after cardiac surgery: incidence and risk factors. Clin Microbiol Infect. 2018;24(3):283-28. https://doi.org/10.1016/j.cmi.2017.07.004.

24. Tadesse BT, Ashley EA, Ongarello S, et al. Antimicrobial resistance in Africa: a systematic review. BMC Infect Dis. 2017;17(1):616. https://doi.org/10.1186/s12879-017-2713-1.

25. Dessie W, Mulugeta G, Fentaw S, Mihret A, Hassen M, Abebe E. Pattern of bacterial pathogens and their susceptibility isolated from surgical site infections at selected referral hospitals, Addis Ababa, Ethiopia. Int J Microbiol. 2016; 2016:2418902. https://doi.org/10.1155/2016/2418902.

26. Mengesha RE, Kasa BG, Saravanan M, Berhe DF, Wasihun AG. Aerobic bacteria in post-surgical wound infections and pattern of their antimicrobial susceptibility in Ayder Teaching and Referral Hospital, Mekelle, Ethiopia. BMC Res Notes. 2014;7:575. https://doi.org/10.1186/1756-0500-7-575.

27. Anguzu JR, Olila D: Drug sensitivity patterns of bacterial isolates from septic post-operative wounds in a regional referral hospital in Uganda. Afr Health Sci. 2007;7(3):148-154.

https://doi.org/10.5555/afhs.2007.7.3.148.

28. Mulu W, Kibru G, Damtie M: Postoperative nosocomial infections and antimicrobial resistance pattern of bacteria isolates among patients admitted at Felege Hiwot Referral Hospital, Bahirdar, Ethiopia. Ethiop J Health Sci. 2012, 22(10):7-18.

29. Manyahi J, Matee MI, Majigo M, Moyo S, Mshana SE, Lyamuya EF. Predominance of multi-drug resistant bacterial pathogens causing surgical site infections in Muhimbili national hospital, Tanzania. BMC Res Notes. 2014;7:500. https://doi.org/10.1186/1756-0500-7-500.

30. Akhi MT, Ghotaslou R, Beheshtirouy S, et al.. Antibiotic Susceptibility Pattern of Aerobic and Anaerobic Bacteria Isolated From Surgical Site Infection of Hospitalized Patients. Jundishapur J Microbiol. 2015;8(7):e20309.https://doi.org/10.5812/jjm.20309v2.

31. Manenzhe RI, Zar HJ, Nicol MP, Kaba M. The spread of carbapenemase-producing bacteria in Africa: a systematic review. J Antimicrob Chemother. 2015;70(1):23-40. https://doi.org/10.1093/jac/dku356.

32. Nordmann P, Poirel L. Emerging carbapenemases in Gram-negative aerobes. Clin Microbiol Infect. 2002; 8(6):321-331.https://doi.org/10.1046/j.1469-0691.2002.00401.x.

33. Tzouvelekis LS, Markogiannakis A, Psichogiou M, Tassios PT, Daikos GL. Carbapenemases in Klebsiella pneumoniae and other Enterobacteriaceae: an evolving crisis of global dimensions. Clin Microbiol Rev. 2012;25(4):682-707. https://doi.org/10.1128/cmr.05035-11.

34. Regev-Yochay G, Smollan G, Tal I, et al.. Sink traps as the source of transmission of OXA-48producing Serratia marcescens in an intensive care unit. Infect Control Hosp Epidemiol. 2018;39(11):1307-1315. https://doi.org/10.1017/ice.2018.235.

35. Percival S.L. 2017. Importance of biofilm formation in surgical infection. Br J Surg. 2017;104(2):e85e94. https://doi.org/10.1002/bjs.10433. 
36. Metcalf DG, Bowler PG. Biofilm delays wound healing: A review of the evidence. Burn Trauma. 2013;1:5-12.

37. Kokare CR, Chakraborty S, Khopade AN, Mahadik KR. Biofilm: importance and applications. Indian J Biotechnol. 2009; 8:159-168.

38. Characklis W G, McFeters G A, Marshall K C. Physiological ecology in biofilm systems. In: Characklis W G, Marshall K C, editors. Biofilms. New York, N.Y: John Wiley \& Sons, Inc.; 1990. pp. 341-394.

39. O'Toole G, Kaplan HB, Kolter R. Biofilm formation as microbial development. Annu Rev Microbiol. 2000; 54:49-79. https://doi.org/10.1146/annurev.micro.54.1.49.

40. Neupane S, Pant ND, Khatiwada S, Chaudhary R, Banjara MR. Correlation between biofilm formation and resistance toward different commonly used antibiotics along with extended spectrum beta lactamase production in uropathogenic Escherichia coli isolated from the patients suspected of urinary tract infections visiting Shree Birendra Hospital, Chhauni, Kathmandu, Nepal. Antimicrob Resist Infect Control. 2016; 5:5. https://doi.org/10.1186/s13756-016-0104-9.

41. Karami, et al. The correlation between biofilm formation capability and antibiotic resistance pattern in Pseudomonas aeruginosa. Gene Reports 18 (2020) 100561. https://doi.org/10.1016/j.genrep.2019.100561.

42. Dumaru R, Baral R, Shrestha LB. Study of biofilm formation and antibiotic resistance pattern of Gram-negative Bacilli among the clinical isolates at BPKIHS, Dharan. BMC Res Notes. 2019;12(1):38. https://doi.org/10.1186/s13104-019-4084-8.

43. Ouedraogo AS, Jean Pierre H, Bañuls AL, Ouédraogo R, Godreuil S. Emergence and spread of antibiotic resistance in West Africa: contributing factors and threat assessment. Med Sante Trop. 2017;27(2):147-154. https://doi.org/10.1684/mst.2017.0678.

\section{Figures}



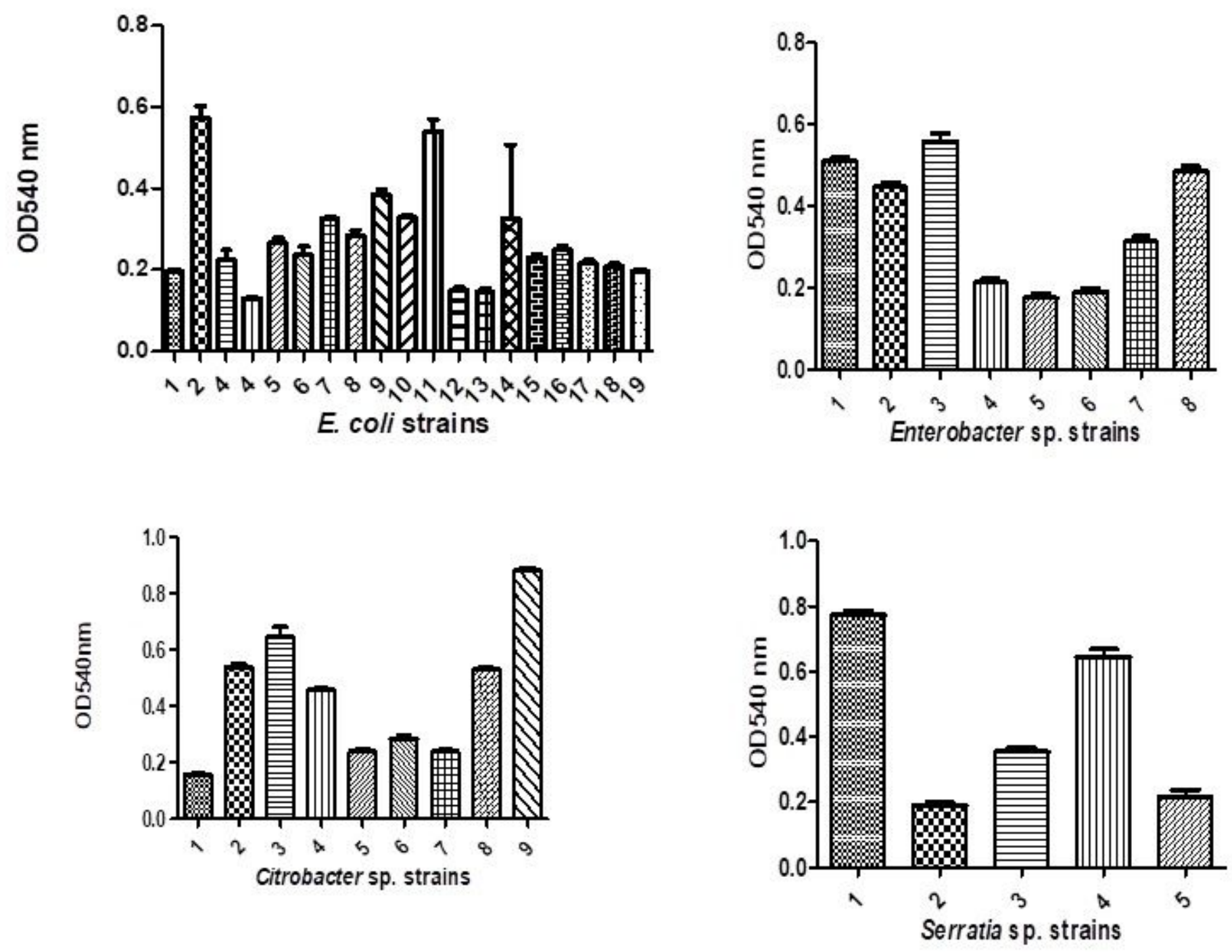

Figure 1

Biofilm formation by Enterobacteriaceae isolates was performed using CVSM. Data are the mean \pm standard deviation of 3 independent experiments. 